Афанасов Н. Б. «Знак священного»: путевой лист Жан-Пьера Аюпюи : рецензия на книгу Жан-Пьера Аюпюи // Философия. Журнал Высшей школы экономики. - 2021. T. 5 , № 4. - C. $347-359$.

\title{
НИКОлАЙ АФАНАСОВ*
}

\section{«ЗНАК СВЯЩЕННОГО»: ПУТЕВОЙ ЛИСТ ЖАН-ПЬЕРА АЮПЮИ}

\author{
РЕЦЕНЗИЯ НА КНИГУ ЖАН-ПЬЕРА АЮПЮИ
}

ДЮПЮИ ЖК.П. ЗНАК СВЯЩЕННОГО / ПЕР. С ФР. А. ЗАХАРЕВИЧ. - М. : НОВОЕ АИТЕРАТУРНОЕ ОВОЗРЕНИЕ, 2021.

DOI: $10.17323 / 2587-8719-2021-4-347-359$.

В 2019-м году Издательство Ивана Лимбаха усилиями переводчицы Анастасии Захаревич познакомило русскоязычного читателя с идеями франко-американского философа Жан-Пьера Дюпюи. Была издана его небольшая работа «Малая метафизика цунами» (Дюпюи, Захаревич, 2019). В своей рецензии на страницах журнала «Galactica Media: Journal of Media Studies» (Афанасов, 2020) я отмечал, что выбор именно этой книги - а всего Дюпюи написал несколько десятков работ - должен оказаться удачным для первого полноценного представления идей философа в России ${ }^{1}$. Спустя два года можно сказать, что это предположение было одновременно верным и неверным. Тираж довольно скоро распродали, а читательские отзывы и рейтинги на профильных сайтах были преимущественно положительными. Перевод следующей книги Дюпюи «Знак священного» (Дюпюи, Захаревич, 2021), которая является предметом настоящей рецензии, не заставил себя долго ждать.

Моя гипотеза основывалась на том, что у Жан-Пьера Дюпюи на тот момент не было весомого кредита доверия со стороны профессионального сообщества российских философов и читателей-интеллектуалов.

*Афанасов Николай Борисович, младший научный сотрудник, сектор социальной философии, Институт философии РАН (Москва), n . af anasov@gmail .com, ORCID: 0000-0001$9183^{-} 3849$.

** (C) Афанасов, Н. Б. (C) Философия. Журнал Высшей школы экономики.

${ }^{1}$ На самом деле впервые на русском с мыслью Дюпюи можно было познакомиться еще в 2006 году в журнале «Отечественные записки», где был опубликован перевод его статьи «Медицина и власть. Памяти Айвана Иллича» (Дюпюи, Каменская, 20о6). Перевод того текста оказался более востребован у специалистов по философским проблемам медицины, чем у социальных теоретиков, исследователей религии или просто интересующихся философией. 
Большинство отечественных исследователей если и знали о Дюпюи, то не упоминали его в своих работах. К достоинствам «Малой метафизики цунами» относится тот факт, что эта книга не слишком абстрактная, она посвящена конкретному нашумевшему случаю - разрушительному землетрясению и цунами в Юго-Восточной Азии в 2004 году; к тому же она небольшая по объему. В жанровом отношении это философское эссе, что как нельзя лучше подходит для первого знакомства со стилем мышления и языком философа. Несмотря на преимущества малой формы, с литературной точки зрения та работа не всегда отвечала ожиданиям читателей. В своем обзоре для сайта газеты «Деловой Петербург» Дмитрий Губин пишет (Губин, 2020):

Не могу сказать, что я «Метафизику цунами» рекомендую любому. Для этого Дюпюи не хватает публицистического мастерства. Ему не хватает силы выстрелить в лоб коротким, простым и понятным тезисом.

Текст Губина критический, а Дюпюи, по мнению автора, не выдерживает сравнения с некоторыми другими интеллектуалами (Насимом Талебом, Александром Секацким). Но основная идея книги все-таки нашла своего читателя, который согласился с тем, что затронутая тема заслуживает внимания: «другой философии катастрофы сегодня нет» (там же).

В 2020 году я писал, что «Малая метафизика цунами» страдает от непоследовательности изложения и оставляет ощущение незавершенности мысли (Афанасов, 2020: 218). Наиболее ценным в книге, на мой взгляд, являлся неординарный подход к катастрофизму. Глобальные катастрофы и проблемы продолжают занимать интеллектуальную публику и профессиональных теоретиков. В воздухе современности витает ощущение того что катастрофа непременно произойдет. И пусть мышление о неизбежности апокалипсиса также может стать предметом критического рассмотрения, в рамках настоящей работы с мыслью Дюпюи вынесем это за скобки. Чтобы читать Дюпюи всерьез, нужно находиться с ним в одном смысловом универсуме: испытывать по меньшей мере смутное ощущение того, что глобальная катастрофа-это не еще один способ пощекотать себе нервы в новых медиа и социальных сетях.

Опыты философского мышления о катастрофе или, выражаясь в более традиционных для российской социальной философии терминах, «глобальных вызовах»-от марксизма до трансгуманизма-предлагают множество интересных мыслительных упражнений, которые, судя по 
всему, не приводят к реальному результату. В конечном счете известный тезис Джеймисона о том, что «легче помыслить конец света, чем конец капитализма» (Фишер, Кралечкин, 2010: 12), остается внешней ограничивающей рамкой мышления о катастрофе: часто социальнофилософский анализ сводится к критике капитализма, который является причиной происходящего, но представить отсутствие которого невозможно. Иными словами, критическая теория часто становится тем, что мыслит о невозможности помыслить катастрофу внутри катастрофы. Бодрийяровская безысходность не оставляет философии шансов. Подход Дюпюи, в основе которого лежит соединение методов аналитической философии, метафизики зла (Гюнтер Андерс, Ханна Арендт) и жирардианства, на первый взгляд выглядит неординарно, а потенциал оригинальной авторской концепции «просвещенного катастрофизма», на мой взгляд, еще не до конца реализован.

Условия издания «Знака священного» отличаются от контекста появления «Малой метафизики цунами». Книга вышла в фундаментальной серии «Studia religiosa» издательства «Новое литературное обозрение». Одной из своих задач книжная серия видит восполнение существующего на русском языке пробела в изучении истории религиозности с самых разных позиций:

В силу идеологизированного отношения к изучению религии в советское время многие ключевые работы в этой области до сих пор недоступны на русском языке. Одна из задач серии - восполнить этот пробел ${ }^{2}$.

Ранее в ней же были изданы важные работы Питера Бергера (Бергер, Сафронов, 2019), Грэма Харви (Харви, Колкунова, 2020), Рене ЖКиpapa (Жирар, Зыгмонт, 2021) и некоторых других теоретиков. «Знак священного» - это книга, которая открывает читателю религиозный генезис и истоки философской мысли Жан-Пьера Дюпюи.

Прежде чем непосредственно перейти к содержанию «Знака священного», я бы хотел сделать несколько методологических замечаний. Приступая к анализу книги Дюпюи, следует точно знать, что именно мы хотим подвергнуть критическому рассмотрению. В зависимости от ракурса оценка работы будет меняться. Чтение может оказаться как разочаровывающим, так и производящим впечатление «откровения». Концептуальная рамка серии «Studia religiosa» ориентирует на «религиоведческое»

\footnotetext{
${ }^{2}$ CM.: https://www.nlobooks.ru/books/studia_religiosa/.
} 
прочтение труда, что подразумевает оценку (возможного) вклада Дюпюи в современные теории религии и религиозно-апокалиптического мышления. В конце концов, Дюпюи пишет: «К самому себе я применяю определение ,христианин-интеллектуал“» (Дюпюи, Захаревич, 2021: 123). В книге действительно много религиозно-философских идей. Они преимущественно христианские по духу и не лишены интеллектуального изящества. Но являются ли они оригинальными? Могут ли они помочь современной философии в поиске решений проблем, наличие которых волнует в том числе и французского философа? Предположу, что по большей части не они будут интересовать читателя.

Композиционно книга состоит из 7 глав и предисловия Алексея Гринбаума (Гринбаум, 2021), который в 2019 году написал небольшой вступительный текст и для «Малой метафизики цунами» (Гринбаум, 2019). На первый взгляд последовательность глав не дает ответа на вопрос, зачем и почему они в книге именно в таком порядке. Главы дополняют друг друга лишь отчасти, а иногда и вовсе производят впечатление никак не связанных друг с другом текстов. По прочтении обнаруживается одно важное обстоятельство: в определенной степени все фрагменты книги тавтологичны. Обращение к разным конкретным сюжетам лишь служит иллюстрацией способности Дюпюи размышлять в рамках своей методологии. Иначе говоря, «Знак священного»-это очень непоследовательная книга, если читать ее в исследовательской парадигме, предполагающей подтверждение методологической установки анализом эмпирического материала. Но, с другой стороны, «последовательность» мысли здесь абсолютная: начав свой исследовательский путь в философии с работ Жирара, Иллича и Андерса, Дюпюи продолжает развивать их идеи, по-видимому искренне полагая, что только так можно справиться с катастрофой. Мысль Жан-Пьера Дюпюи замыкается в кругу авторов и времени катастрофы. В этот круг он желал бы включить и своего читателя.

Завершая введение в книгу, Дюпюи, будто подозревая, что читатель может вполне резонно обвинить его в непоследовательности, пишет (Дюпюи, Захаревич, 2021: 38):

Идеей этой книги я обязан своему издателю и другу Бенуа Шартру. Мои философские работы последних пятнадцати лет оставляют впечатление некоторой эклектичности, в том числе и у меня самого. [...] Бенуа сумел найти связующую их нить Ариадны. Отобрав несколько работ, он заставил меня переписать их так, чтобы стала видна общая линия. 
Напомню, что книга была издана во Франции в 2009 году. «Знак священного» - это работа, которая подытоживает теоретические наработки французского мыслителя за предшествующие году издания несколько десятилетий. Возможно, издатель Дюпюи господин Шартр счел необходимым помочь систематизировать мысль философу, который сам не ставил перед собой подобной задачи. По духу и характеру лирических отступлений, а также экскурсов в собственную биографию у читателя книги может сложиться впечатление, что Дюпюи подводит окончательные итоги своей профессиональной деятельности. Это не совсем так. Французский философ продолжает активно публиковаться: каждые несколько лет у него выходит по книге. В частности, в 2019 он издал работу, посвященную метафизике ядерной войны (Dupuy, 2019), а в 2021 году опубликовал монографию о жизни во времена пандемии (Dupuy, 2021). Беглый взгляд на эти работы позволяет утверждать, что ЖанПьер Дюпюи продолжает придерживаться ранее разработанных идей.

Композиционные и стилистические особенности книги делают последовательное изложение и анализ идей «Знака священного» бессмысленными. Он был бы интересен лишь тем, кто предметно интересуется генезисом мысли автора, а это предполагает вдумчивое чтение. Думаю, что «Малая метафизика цунами» не создала для французского философа тот кредит доверия, чтобы частности его интеллектуального пути интересовали широкую публику. Постараемся взглянуть на работу с точки зрения ее смысловой структуры. Для того чтобы понять, имеет ли вообще работа Дюпюи какую-либо важность, рассмотрим несколько стержневых тем, которые есть в книге. Во-первых, автор предлагает поиск игнорируемых, забытых религиозных основ, являющихся фундаментом всех современных социально-политических феноменов. Во-вторых, он проводит философский анализ «просвещенного катастрофизма». И, наконец, в книге есть несколько набросков автора о том, почему Хичкок хорош, ресентимент губителен, а нам всем нужно смотреть побольше фильмов и сериалов. Мы обратимся к каждой из тем и в заключении попытаемся дать ответ на вопрос, может ли Дюпюи быть актуален для решения - по меньшей мере философского проблемы возможного 3 апокалипсиса.

3 Для Дюпюи «апокалипсис» или «Катастрофа» не только возможны, но и логически обязательны. Тем не менее, занимая критическую позицию, мы будем говорить об этих событиях как о гипотетических. 
В своей рецензии на книгу для портала «Горький» исследователь мысли Рене Жиирара Алексей Зыгмонт пишет (Зыгмонт, 2021):

«Знак» в заглавии книги-не signe, a marque, то есть «метка». Такая трактовка позволяет лучше уяснить себе цель книги: в качестве рудимента, рецидива или «скрытой и неосознаваемой структуры» отыскать священное в областях, которые якобы от него свободны, - таких, как экология, наука, экономика, демократическое голосование, этическая теория, международная политика в формате ядерного сдерживания и прочее.

Обращение к религиозному выступает возможностью понять, как устроены человек и общество. Дюпюи пишет, что

разум сохраняет нестираемый след религиозного опыта, в который уходит корнями. Вслед за Дюркгеймом религиозное здесь определяется не столько через убеждения, сколько через действия - не через веру, а через ритуал (Дюпюи, Захаревич, 2021: 16).

Дюпюи, вслед за Жираром, ищет нередуцируемое «священное» в современном мире. Его мысль в отношении религиозного оказывается существующей в хорошо знакомой парадигме размышлений о генезисе множества современных феноменов: от естественнонаучных дисциплин до политической теологии. Их становление проходило под влиянием функционирования религиозных институтов и мышления и в тесном взаимодействии с ними. В конечном счете наука, общественные структуры, экономика и, по-видимому, практически все известные нам сегодня социальные феномены содержат в своей основе элементы религиозного, «священного». Дюпюи полагает, что «мы уже внутри» реальности священного (там же: 121):

Мы уже внутри, уже проникнуты религиозным так же, как социальноисторическим, даже если критикуем его или намерены его демистифицировать.

Социальное начинает давать сбой в своем функционировании тогда, когда мы об этом забываем. Дюпюи уверен, что нужно об этом напомнить.

В основе цивилизации лежит давно забытая трагическая близость насилия и священного (там же: 133):

История человечества - это история эндогенной эволюции жертвенных систем: цивилизация совершает скачок вперед каждый раз, когда человеческая жертва заменяется сначала на животную, затем на растительную, а еще позднее на абстрактные символические сущности. Это история символизации. 
С точки зрения истории философии мысль Жан-Пьера Дюпюи вторична по отношению к мысли Рене Жирара. По всей видимости, Дюпюи не видит перед собой задачу не только как-то модифицировать, но и прояснить для более широкого - Дюпюи востребованный автор в кругу непрофессиональных философов (Гринбаум, 2019) - читателя теорию Жирара. Дюпюи полностью принимает его оптику, согласно которой христианство победило в современном мире, а его неотрефлексированная, забытая обществом победа лишь плодит насилие (Дюпюи, Захаревич, 2021: 153-154). Осознание повсеместности насилия и конкуренции, теоретические основы которых были позаимствованы у Рене Жирара, были тем, что привело Дюпюи к его апокалиптической философии.

Жан-Пьер Дюпюи сумел стать популярным философом среди тех, кто интересуется философией в силиконовой долине, но не занимается ей профессионально. Этого не удалось сделать ни Гюнтеру Андерсу, ни Рене Жирару, мысль которых лежит в основе философско-религиозной рефлексии Дюпюи. За счет чего этого удалось достичь? Я полагаю, что решающими оказались два фактора. Если абстрагироваться от личных организаторских способностей француза, его инженерного образования, то на содержательном уровне он, во-первых, сумел ясно изложить логику неминуемой катастрофы, обратившись к тем, кто это катастрофу приближает своей деятельностью (то есть к активным экономическим субъектам, встроенным в (вос)производство динамичной капиталистической реальности). Во-вторых, Дюпюи занялся наиболее популярной темой современности - экологией.

Первая и предпоследняя, шестая глава Дюпюи посвящены мировой катастрофе-как гласит подзаголовок к другой его книге, «невозможной и неизбежной». Образ ее в целом сводится к экологическому коллапсу, который приведет человечество на грань - а может, сразу за грань - вымирания. Вызвана эта катастрофа будет двумя причинами, которые совпадают с позициями двух ключевых для Дюпюи фигур: это насилие между людьми (Жирар) и неумеренный прогресс технологий (Иллич) (Зыгмонт, 2021).

«Знак священного» в очередной раз представляет вниманию читателя концепцию «просвещенного катастрофизма», которая занимает Дюпюи последние несколько десятилетий. Я полагаю, что это наиболее ценная составляющая и этой книги, и вообще актуального на данный момент творчества французского философа. В наиболее развернутом и аналитическом виде она представлена в отдельном труде «Ради просвещенного катастрофизма» (Dupuy, 2004). Дюпюи склонен повторять 
одни и те же идеи несколько раз, облекая их в разную форму, и иллюстрировать их одними и теми же примерами, поэтому формулировок концепции «просвещенного катастрофизма» у него несколько. В чем ее смысл? Говоря просто, согласно теории просвещенного катастрофизма: а) катастрофа логически неизбежна в силу причин, лежащих в основе устройства человеческого общества (конкуренции, забытого «священного» и проч.), б) для того чтобы предотвратить катастрофу, нужно поверить в ее неизбежность и невозможность ее предотвращения, в) принимая катастрофу всерьез и действуя, человечество лишь успокаивает себя, г) предпринимаемых мер никогда не будет достаточно, потому что устройство общества остается неизменным.

Разберем по пунктам логику теории. Катастрофа логически неизбежна, поскольку разворачивание базовых механизмов, лежащих в основе функционирования социума, неминуемо к этому ведет. Дюпюи не хочет усложнять свою мысль, напротив, как ангажированный философпророк, он использует максимально простые примеры и адаптирует их для аудитории не всегда владеющей философией на профессиональном уровне (Дюпюи, Захаревич, 2021: 194):

Философ и моралист Адам Смит прекрасно знал, что богатства желают не из-за приносимых им скромных материальных радостей, а оттого, что его желают другие.

Эта простая и известная формула предопределяет невозможность кониа, которая ведет к Кониу. Иными словами, потребление и конкуренция между людьми, обществами, странами не ограничены ничем, потому что их точками отсчета выступают состояния и желания других. Это бесконечный процесс, не принимающий в расчет физических ограничений, которые, как полагает Дюпюи, присутствуют в нашем мире. Поскольку формула именно логическая, ее эмпирическое наполнение можно предоставить фантазии читателя.

Конкуренция ничем не ограничена, и жажда отличия, «самолюбие» никогда не будут полностью удовлетворены (там же: 209):

Известно, что Руссо называл «самолюбием» квинтэссенцию человеческого желания-силу, которая движет людьми, порождая в них все пороки.

Допустим, что это известно многим. Предположим также, что некоторые из этих многих могли самостоятельно или в крайнем случае при помощи Жан-Пьера Дюпюи (или Рене Жирара, Ханны Арендт, Айвана Иллича, Жан-Жака Руссо и многих других) прийти к мысли 
о своей порочности и порочности общества. Дело в том, что последний шаг мысли всегда терялся в размытых формулировках и исторических деталях. Дюпюи же категоричен: апокалипсис произойдет, и речь идет о глобальной катастрофе.

Оказывается, что за определенным порогом наша способность совершать действия неизбежно и неизмеримо превосходит способность ощущать или воображать их последствия (Дюпюи, Захаревич, 2021: 231).

В начале рецензии я писал, что современное мышление о катастрофизме фокусируется на капитализме и его внутренних противоречиях. Жан-Пьер Дюпюи, казалось бы, вновь встраивается в эту логику критики капиталистической системы с позиции ее логически необходимой конечности (там же: 193):

Именно в области экономики отрицание религиозной основы человеческих обществ - предмет этой книги - приводит, вероятно, к самым губительным последствиям.

Однако его мысль отличается от традиционной критики неограниченного накопления и инструментального преобразования окружающей среды по меньшей мере в двух аспектах. Во-первых, Жан-Пьер Дюпюи видит истоки экономики вне нее. Возможно, это поможет кому-либо вообразить, что с этим можно сделать. Во-вторых, Дюпюи не дает никаких практических рекомендаций. Это может показаться недостатком, ноесли находиться в логике философии Дюпюи - любая практическая рекомендация лишь переносит Конеи, во времени. Решения должны быть из иной плоскости, и, по-видимому, сам Дюпюи не может предложить ничего конкретного. В этом проявляется интеллектуальная честность книги: автор видит, что предпринимаемые шаги не работают и не могут работать, но отбросить мысль о необходимости поисков не может.

Помимо стержневой темы «просвещенного катастрофизма» и религиозно-философской рефлексии над состоянием современной экономики и общества «Знак священного» может предложить читателю несколько небезынтересных отступлений, актуальных для современной повестки. Одно из них касается «идеологии жертвенности» (Гринбаум, 2021: 11). Речь идет о том, что притесняемые группы, «жертвы», никогда не смогут удовлетворить свою претензию на справедливость: в глазах «жертвы» насильник бесконечно виновен. Таким образом, подобно описанному выше механизму безграничного желания, искуплением может стать лишь полное уничтожение зла. Этот ресентимент разрушает 
социальное пространство, упраздняет возможность любого диалога. В основе «жертвенности» лежит забытое священное. Это отступление показывает, насколько полезна может быть логика религиозного при понимании некоторых актуальных социальных феноменов. Соответственно, помимо самоценности разбираемого сюжета, Дюпюи хочет придать дополнительный теоретический вес своим общим построениям.

Еще одно отступление несет в себе нечто, что редко можно обнаружить в работах Дюпюи. Впервые он пишет то, о чем не писал раньше: «Скажу одно: об этом произведении („Головокружение“ Альфреда Хичкока - H. A.) я говорю впервые» (Дюпюи, Захаревич, 2021: 246). Анализируя фильм Хичкока, французский философ поясняет свою метафизику времени катастроф, целью которой является обосновать возможность предотвращения неизбежного (там же: 261):

В центре моих размышлений о катастрофах та же метафизика времени-круг, связывающий будущее с прошлым и прошлое с будущим. [...] Проектированное время - так [...] я назвал эту метафизику. [...] Благодаря метафизическому действию совершенного будущего оно обретает черты фиксированного прошлого. Если зацикливания не происходит, то проектированное времяметафизический вымысел-открыто являет этот статус: то, чего, если посмотретъ из будущего, не случилось, разрушается от встречи с самим собой.

Выход из логического парадокса «просвещенного катастрофизма» лежит в особой метафизике времени Дюпюи. За этим же французский философ и рекомендует нам чаще обращаться к художественным произведениям, смотреть фильмы, читать романы. Опыты веры в художественный вымысел помогут не погибнуть в диалектике катастрофизма (там же: 241):

Мы не должны ни верить в судьбу слишком сильно, ни отказываться от этой веры начисто. Иначе говоря, в судьбу нужно верить так, как верят в художественный вымысел. [...] Эта структура в точности совпадает со структурой изначального священного у Рене Жирара.

«Знак священного»- спорная книга. Во многих отношениях она непоследовательна - иными словами, повторяет, не привнося дополнительной ясности, уже проговоренные Дюпюи мысли и аргументы. Я полагаю, что замысел издателя и друга Дюпюи господина Шартра получил двоякую реализацию. Для тех, кто уже интересовался мыслью Дюпюи, «Знак священного» станет повторением не всегда ясных мыслей и идей прошлого под одной обложкой. Для тех, кто захочет найти комментарий к функционированию священного в мире, работа окажется вторичной на 
фоне трудов Рене Жирара, Айвана Иллича и Гюнтера Андерса. Более того, вполне возможно, что самой интересной «теоретической» книгой Дюпюи останется непереведенный на русский язык «Просвещенный катастрофизм». Эта работа также написана очень сложным языком и лишена обширных пояснений, но теория в ней содержится в концентрированном виде, а повествование не прерывается не всегда полезными примерами и историями. На профессиональном уровне работать с ней было бы проще, а для широкого круга читателей и неспециалистов «Знак священного» окажется тяжелым времяпрепровождением.

Дюпюи пишет: «Апокалипсис как судьба начертан в нашем будущем, и лучшее, что мы можем сделать, это отдалить его на неопределенное время» (Дюпюи, Захаревич, 2021: 230). По всей видимости, это и есть авторская позиция, цель книги, та самая часть порочного логического круга «просвещенного катастрофизма», когда философия катастрофы становится художественным вымыслом, в который мы должны поверить. Чтобы предотвратить катастрофу, нужно поверить в невозможность ее предотвращения. Только тогда действия, пропитанные религиозной безысходностью и одновременно бесплодной надеждой, возможно, смогут нас всех спасти:

действительное принятие апокалиптической позиции сегодня - более, чем когда-либо, - это единственный способ сохранить трезвость рассудка (Žižek, 2012).

\section{ЛИТЕРАTУРA}

Афанасов Н. Б. «Траур по будущему», или Картография апокалипсиса // Galactica Media : Journal of Media Studies. - 2020. - T. 2, № 1. - C. 205-220.

Бергер П. Священная завеса. Элементы социологической теории религии / пер. с англ. Р. Сафронова. - М. : Новое литературное обозрение, 2019.

Гринбаум А. Предисловие // Малая метафизика цунами / Ж.-П. Дюпюи ; пер. с фр. А. Захаревич. - СПб. : Издательство Ивана Лимбаха, 2019. - С. $5^{-16}$. Гринбаум А. Предисловие // Знак священного / Ж.-П. Дюпюи ; пер. с фр. А. Захаревич. - М. : Новое литературное обозрение, 2021. - С. $7^{-15}$.

Губин Д. Философия и пошлость катастрофы. «Малая метафизика цунами» Жан-Пьера Дюпюи / Деловой Петербург. - 2020. - URL: https://www.dp.r u/a/2020/04/24/Filosofija_i_poshlost_kata (дата обр. 1 апр. 2021).

Дюпюи Ж.-П. Медицина и власть. Памяти Айвана Иллича / пер. с англ. Е. Каменской // Отечественные записки. - 2006. - Т. 3, № 1. - С. 7-22. Дюпюи Ж.-П. Знак священного / пер. с фр. А. Захаревич. - М. : Новое литературное обозрение, 2021. 
Жирар Р. Ложь романтизма и правда романа / пер. с фр. А. Зыгмонта. -

М. : Новое литературное обозрение, 2021.

Зыгмонт A. Чёрная метка прогресса / Горький. - 2021. - URL: https://gork y.media/reviews/chernaya-metka-progressa/ (дата обр. 1 июня 2021).

Фишер М. Капиталистический реализм / пер. с англ. Д. Ю. Кралечкина. М. : Ультракультура 2.0, 2010.

Харви Г. Секс, еда и незнакомцы. Религия как повседневная жизнь / пер. с англ. К. Колкуновой. - М. : Новое литературное обозрение, 2020.

Dupuy J.-P. Pour un catastrophisme éclairé. - Paris : Seuil, 2004.

Dupuy J.-P. La guerre qui ne peut pas avoir lieu : Essai de métaphysique nucléaire. Paris : Éditions Desclée de Brouwer, 2019.

Dupuy J.-P. La catastrophe ou la vie. Penseés par temps de pandémie. - Paris : Seuil, 2021.

Žižek S. A Modest Plea for Enlightened Catastrophism / ABC Religion \& Ethics. 2012. - URL: https://www.abc.net.au/religion/a-modest-plea-for-enlightene d-catastrophism/10100430 (visited on Apr. 1, 2021).

Afanasov, N. B. 2021. “'Znak svyashchennogo': putevoy list Zhan-P'yera Dyupyui ['La Marque du Sacré': Jean-Pierre Dupuy's Travel Log]: retsenziya na knigu Zhan-P'yera Dyupyui [Review of a Book by J.-P. Dupuy]" [in Russian]. Filosofiya. Zhurnal Vysshey shkoly ekonomiki [Philosophy. Journal of the Higher School of Economics] 5 (4), 347-359.

\author{
NiKOLAY AfANASOV \\ JUNIOR RESEARCHER \\ Social Philosophy Department, RAS Institute of Philosophy (Moscow, Russia); \\ ORCID: 0000-0001-9183-3849
}

\title{
"LA MARQUE DU SACRE": JEAN-PiERRE DUPUY'S TRAVEL LOG REVIEW OF A BOOK BY J.-P. DUPUY
}

DupuY, J.-P. 2021. ZNAK SVYASHCHENNOGO [LA MARQUE DU SACRÉ] [IN RusSian]. TRANS. From the French by A. ZaKharevich. Moskva [Moscow]: Novoye Literaturnoye OBOZRENIYE

DOI: $10.17323 / 2587-8719-2021-4-347-359$.

\section{REFERENCES}

Afanasov, N. B. 2020. "'Traur po budushchemu', ili Kartografiya apokalipsisa ['Mourning for the Future', or the Cartography of Apocalypse]" [in Russian]. Galactica Media [Galactica Media]: Journal of Media Studies [Journal of Media Studies] 2 (1): 205-220. 
Berger, P. 2019. Svyashchennaya zavesa. Elementy sotsiologicheskoy teorii religii [The Sacred Canopy. Elements of a Sociological Theory of Religion] [in Russian]. Trans. from the English by R. Safronov. Moskva [Moscow]: Novoye literaturnoye obozreniye.

Dupuy, J.-P. 2004. Pour un catastrophisme éclairé [in French]. Paris: Seuil.

. 2006. "Meditsina i vlast'. Pamyati Ayvana Illicha [Medicine and Power. A Tribute to Ivan Illich]" [in Russian], trans. from the English by Ye. Kamenskaya. Otechestvennyye zapiski [Fatherland Notes] 3 (1): 7-22.

. 2019a. La guerre qui ne peut pas avoir lieu: Essai de métaphysique nucléaire [in French]. Paris: Éditions Desclée de Brouwer.

- 2021a. La catastrophe ou la vie. Penseés par temps de pandémie [in French]. Paris: Seuil.

. 2021b. Znak svyashchennogo [La marque du sacré] [in Russian]. Trans. from the French by A. Zakharevich. Moskva [Moscow]: Novoye literaturnoye obozreniye.

Fisher, M. 2010. Kapitalisticheskiy realizm [Capitalist Realism] [in Russian]. Trans. from the English by D. Yu. Kralechkin. Moskva [Moscow]: Ul'trakul'tura 2.0.

Girard, R. 2021. Lozh' romantizma i pravda romana [Mensonge romantique et verité Romanesque] [in Russian]. Trans. from the French by A. Zygmont. Moskva [Moscow]: Novoye literaturnoye obozreniye.

Grinbaum, A. 2019. "Predisloviye [Foreword]" [in Russian]. In Malaya metafizika tsunami [Petite métaphysique des tsunamis], by J.-P. Dupuy, trans. from the French by A. Zakharevich, 5-16. Sankt-Peterburg [Saint Petersburg]: Izdatel'stvo Ivana Limbakha.

- 2021. "Predisloviye [Foreword]" [in Russian]. In Znak svyashchennogo [La marque du sacré], by J.-P. Dupuy, trans. from the French by A. Zakharevich, 7-15. Moskva [Moscow]: Novoye literaturnoye obozreniye.

Gubin, D. 2020. 'Filosofiya i poshlost' katastrofy. 'Malaya metafizika tsunami' Zhan-P'yera Dyupyui [Philosophy and Vulgarity of the Catastrophy. Jean-Pierre Dupuy's 'A Short Treatise on the Metaphysics of Tsunamis']" [in Russian]. Delovoy Peterburg. Accessed Apr. 1, 2021. https://www.dp.ru/a/2020/04/24/Filosofija_i_poshlost_kata.

Harvey, G. 2020. Seks, yeda i neznakomtsy. Religiya kak povsednevnaya zhizn' [Food, Sex and Strangers. Understanding Religion as Everyday Life] [in Russian]. Trans. from the English by K. Kolkunova. Moskva [Moscow]: Novoye literaturnoye obozreniye.

Žižek, S. 2012. "A Modest Plea for Enlightened Catastrophism." ABC Religion \& Ethics. Accessed Apr. 1, 2021. https://www.abc.net.au/religion/a-modest-plea-for-enlightened-ca tastrophism/10100430.

Zygmont, A. 2021. "Chërnaya metka progressa [The Black Spot of Progress]" [in Russian]. Gor'kiy. Accessed June 1, 2021. https://gorky.media/reviews/chernaya-metka-progressa/. 